\title{
Inmigración y prostitución: el caso del Raval (Barcelona)
}

\section{Sara Carmona Benito}

Instituto de Cooperación con el Mundo Árabe Agencia Española de Cooperación Internacional Avda. Reyes Católicos, s/n. Madrid

\section{Resumen}

El presente estudio analiza las condiciones de vida de un grupo de mujeres inmigrantes marroquíes que trabajan como prostitutas en un barrio de la ciudad vieja de Barcelona. Para estas mujeres, la prostitución representa una actividad que puede prometer el acceso a uno de los objetivos principales de la emigración: la acumulación de dinero en mayor cantidad, o con mayor rapidez que lo puedan ofrecer otros puestos de trabajo como el servicio doméstico o el cuidado no cualificado de personas, siendo éstas las opciones ofertadas prioritariamente para las mujeres inmigrantes en esta ciudad. Estas mujeres trabajan ocultas de sus familias y con la complicidad de sus paisanos. Unas veces con objetivos planificados y otras con la dificultad a aceptarse a sí mismas y a sus circunstancias.

Palabras clave: inmigración y prostitución marroquí, Barcelona, barrio del Raval.

\section{Abstract. Immigration and prostitution: the case of the Raval (Barcelona)}

This study analyses the living conditions of a group of Moroccan immigrant women who earn their living as prostitutes in an old quarter of Barcelona. Prostitution is an activity which may offer a way to achieve the aims of migration, to earn money in larger amounts, or quicker, than may be possible in other kinds of work typically available to immigrant women in Spain, such as domestic help or the unqualified care of people. Moroccan immigrant prostitutes in the Raval work hidden from their families and with the complicity of their fellow countrymen, sometimes with clear objectives and sometimes with problems of accepting themselves and their circumstances.

Key words: immigration and Moroccan prostitution, Barcelona, quarter of El Raval.

\section{Sumario}

1. Introducción a un pequeño estudio etnográfico

2. El proceso emigratorio

3. ¿Por qué emigran, en qué casos?

4. La inmigrante marroquí como prostituta en el Raval

5. Inducción a la prostitución
6. Respecto a la regulación de la prostitución ejercida

7. Respecto a la clientela

8. La inaceptación moral

de la prostitución

Bibliografía 


\section{Introducción a un pequeño estudio etnográfico}

Según Juliano (1998: 59), las inmigrantes extracomunitarias se encuentran en la sociedad de acogida trabajos en que resultan discriminadas por género, precisamente porque eran los lugares de trabajo tradicionalmente femeninos que liberan las mujeres españolas. Las inmigrantes heredan así la discriminación salarial, al mismo tiempo que se ven empujadas a otras actividades consideradas indignas o peligrosas como la prostitución. Este tipo de trabajo ya ha sido desvalorizado previamente en tanto que femenino, con su connotación religiosa de pecado e impureza.

Nos situamos en Barcelona, gran ciudad en España atractora de inmigración. Una ciudad enmarcada dentro de lo que se entiende como una sociedad moderna, avanzada, occidental; en la cual se desarrolla la vida de unas personas inmigrantes del sur, de cultura árabe y beréber, y, en ocasiones, no urbanas. Y en este contexto nos hemos ubicado en el barrio del Raval. Un centro histórico degradado (ahora, en proceso de rehabilitación urbana), y hacinado; habitado por un número considerable de inmigrantes del sur, y principalmente de marroquíes. En el seno de este barrio está el denominado popularmente «barrio chino", una zona de gran tradición de prostitución callejera que además, como buena ciudad de puerto, ha configurado el carisma de Barcelona junto a otras características que la han hecho famosa, como el Modernismo, el Barrio Gótico, Copito de Nieve, o los cabarets del Paralelo como el Molino o Bagdad, centro de pornografía en vivo.

El presente análisis se realizó entre enero y junio de 1996, con el objetivo de describir las condiciones de vida de la prostituta marroquí que trabajaba en este barrio desde la perspectiva del itinerario recorrido por esta mujer desde la emigración hasta la inserción en la prostitución una vez en Barcelona.

Hemos pretendido constatar que, en primer lugar, las prostitutas marroquíes, por ser extranjeras "pobres», cuentan con una inferioridad de condiciones laborales y sociales respecto a las prostitutas españolas. En segundo lugar, la prostitución representa para estas mujeres una forma más de ganarse la vida; una forma más o menos asumida por las mujeres que se prostituyen, que varía entre las personas según su sistema moral.

La entrevista en profundidad ha sido la herramienta básica de trabajo. Se han entrevistado, por un lado, diferentes actores sociales relacionados con temas que tienen que ver con la inmigración, la condición de la mujer o las condiciones de vida de las prostitutas ${ }^{1}$. Por otro lado, este trabajo de entrevistas se compa-

1. Los entrevistados han sido:

1) El equipo de atención a la mujer del Ayuntamiento de Barcelona.

2) El punto de información, asesoramiento, orientación y asistencia social al inmigrante «SAIER»: Servicio de Atención al Inmigrante Exterior y Refugiado; colaboración de diferentes entidades: Cruz Roja, El Colegio de Abogados de Barcelona, Comisiones Obreras y ACSAR.

3) Distintos organismos dedicados a la asistencia social en el barrio:

a) Las hermanas Oblatas; orden religiosa que tiene una larga tradición de trabajo con mujeres que viven en la calle, en especial las prostitutas. 
ginó con una constante observación participante en las manzanas donde se ubica la prostitución callejera y entrevistas a siete prostitutas repartidas entre las tres calles del estudio (calle D'en Robador, calle Sant Ramon y Ronda de Sant Antoni). En cuanto a los detalles de la observación participante con las mujeres, hemos de incluir largas conversaciones en las que se desvelan sus comentarios sobre la prostitución, sus inquietudes respecto al trabajo, además de sus formas de desahogo y bromas respecto a la situación en que viven.

Las mujeres tienen entre 23 y 48 años $^{2}$ (con apariencia de mayor edad a la que les corresponde, sobre todo entre las veinteañeras). La mayoría eran inmigrantes de primera generación, madres de familia con hijos. Sin embargo, también se da el caso de hijas de inmigrantes que no se entendían con los padres, que las hacían seguir las tradiciones más ortodoxas junto con la necesidad de éstas por conseguir un mayor espacio de «libertad», con la finalidad de poder seguir «las nuevas modas y hábitos occidentales» (caso de Sara $4^{3}$ ). La mayor parte de ellas procede de un contexto familiar desestructurado, son chicas que han roto las relaciones con sus familias y que han tenido que empezar a ganarse la vida por sí mismas.

Por esta trayectoria de ruptura familiar en el origen son mujeres que han optado por un tipo de «emigración femenina autónoma», representando la antítesis al modelo típico de reunificación familiar imperante en las migraciones mediterráneas. En general, son mujeres que han emigrado solas y que están aquí sin marido y sin familia.

Excepto dos mujeres (de las siete entrevistadas), todas están sin pareja oficial/legal, libres de marido. Según explican todas las entrevistadas y otras inmi-

b) Cáritas.

c) Centro Salvador Gavina; centro abierto para niños necesitados, que ofrece todo tipo de apoyo y ayudas para el posible desarrollo del niño.

4) Distintas asociaciones para inmigrantes preocupadas por el tema de la integración:

a) Asociación "Bayt al Thaqafa»; centro de reunión para actividades culturales orientadas a la creación de grupos de apoyo entre los inmigrantes con el fin de conseguir una mejor integración a la nueva sociedad, sobre todo acuden al centro mujeres y los hijos de éstas. A pesar de su ubicación en el barrio de la Ribera, acoge a inmigrantes del Raval.

b) «Ca la Dona»; centro para la reunión de distintos grupos de mujeres, inspiradas por una lucha reivindicativa hacia la igualdad de oportunidades para ellas. Dentro del centro existe un grupo de mujeres marroquíes, que luchan por mostrarse como mujeres, inmigrantes, marroquíes, defendiendo una cierta lucha por la autonomía de la mujer marroquí en Barcelona.

5) Distintos agentes de salud:

a) Ginecólogo privado de la calle Sant Ramon.

b) Centro Municipal de Planificación Familiar de Drassanes (hoy trasladado).

c) Farmacia de la calle Sant Ramon (hoy desaparecida).

2. La edad es una variable muy importante en el mundo de la prostitución, porque se trata de un elemento clave para la tarificación de los servicios. Las más jóvenes son las mejores pagadas.

3. Llamaremos Sara con un número distinto a cada una de las prostitutas, pues, en un grupo de siete hemos encontrado que tres han elegido llamarse Sara (todas se cambian el nombre para ser mínimamente reconocidas). Así pues, a la Mari Pili española podría asemejarse la Sara marroquí. 
grantes, estas dos mujeres son ciertamente una excepción, porque una mujer marroquí casada o comprometida difícilmente podría trabajar en la prostitución; pues según sus argumentos el varón-pareja (marido o novio), no ha sido educado como para "consentir» que le tachen su honor a través de la estigmatización que pesaría sobre él por el hecho de tener una mujer infiel y que fuese además una mala madre, una puta (sharmuta, en árabe dialectal marroquí). Todas ellas están libres de sus familias; con la excepción de alguna hermana que guarda el secreto y niños y niñas a los que se les oculta la actividad laboral de la madre. Curiosamente, es interesante señalar como el adjetivo prostituta se utiliza frecuentemente en Marruecos para clasificar a la mujer que no es «una mujer de la casa». Ribas (1996) pudo constatar, en su trabajo de campo, como entre muchos marroquíes existe la idea de que las mujeres que se marcharon a España era para ejercer la prostitución. Este adjetivo está relacionado con las prohibiciones a la movilidad autónoma de la mujer; las prostitutas se saltarían, pues, esta regla y serían las transgresoras por excelencia.

Normalmente conviven con otra persona; no obstante, Sara6 y Sara7 están con sus hijos e hijas. El resto no reside con ningún familiar directo; para ellas han sido las circunstancias del proceso migratorio las que las han obligado a vivir alejadas del ámbito familiar, habiendo roto con éste por el hecho de que la mujer se marchase sola de la familia y del país.

Para las que tienen allí sus hijos e hijas, es muy probable que la estrategia migratoria se base en una pretensión de ahorro para poder acumular capital hasta posibilitar un retorno más o menos delimitado, señalando que prefieren el retorno a que sus hijos residentes ahora en Marruecos viniesen aquí a Barcelona. Sus experiencias como prostitutas en España les marca con un recuerdo que parece que en Marruecos podrían llegar a olvidar. En sus discursos se establecen límites claros de dinero y de tiempo, viajan cuando pueden hacerlo, se comunican con sus hijos desde aquí, fomentan que sus hijos estudien en Marruecos, pero siempre se intenta evitar que lleguen a España. Parecería ser como si para estas mujeres no hubiera una disociación entre la inmigración y el ejercicio de la prostitución. Los dos van siempre unidos, pues representan los medios para salir de su precaria situación personal y económica.

Todas las mujeres guardan relación con sus orígenes en Marruecos, aunque sea indirectamente; sobre todo porque aquí están solas y allí está la familia más directa, la familia nuclear, que es con las que se consideran que tienen los lazos más fuertes.

Todas viven en el barrio del Raval (excepto Sara6, que reside en Sant Gervasi). En el barrio la prostitución es obvia, es visible, es practicada por mujeres de fuera del barrio pero también por algunas que allí residen (porque ya residían antes de trabajar en el oficio o porque está próxima a la zona de trabajo). Otras mujeres del barrio (tanto extranjeras como autóctonas), suelen dedicarse a lo que denominan «fregar suelos» o al «trapicheo».

Las mujeres marroquíes que viven en el barrio y en similares condiciones económicas que las otras mujeres del Raval (mujeres procedentes de las migra- 
ciones interiores del resto de España), comparten una situación de carencia de recursos económicos, y además ejercen el mismo tipo de actividades económicas: servicio doméstico, trapicheo, prostitución; son las tres posibilidades existentes para las mujeres en el medio socioeconómico y espacial en el que se mueven.

\section{El proceso emigratorio}

Las entrevistadas proceden de las mismas zonas que la población inmigrante marroquí en España; con la excepción de que la mayoría de marroquíes en Cataluña proviene de la provincia de Nador. No obstante, ésta es a su vez la provincia de la que menos mujeres emigran con relación al número de hombres. Las mujeres marroquíes que viven en España proceden mayoritariamente de la región norteña de la Yebala ${ }^{4}$; igual que ocurre con nuestro pequeño grupo de entrevistadas.

Las mujeres entrevistadas llevan viviendo en España entre siete y nueve años, excepto Sara6, que está aquí desde hace veintiún años, y Sara1, que está residiendo en España desde hace cuatro años. Todas vinieron directamente hacia Barcelona excepto Sara5, que pasó primeramente un año en Málaga, de ahí seis en Lérida y ahora lleva un año en Barcelona, y Sara4, que se fue a Lérida directamente y ahora lleva tres años en Barcelona. No hemos detectado ninguna trayectoria típica en los saltos entre destinos migratorios. Usan Barcelona como puerto de entrada porque tienen aquí a la familia y/o conocidos o porque querían probar suerte en una ciudad grande. En este último caso, esta ciudad grande podría ser cualquiera, era una ciudad escogida al azar puesto que no conocían a nadie aquí.

En nuestros siete casos vinieron solas, sin compartir la iniciativa ni la decisión de emigrar con nadie, y estar sometidas a ningún tipo red que comercia con «la trata de blancas». Se trata pues de una inserción en la prostitución de forma totalmente voluntaria, aparte de las constricciones socioeconómicas en las que tomaron su decisión.

Entraron en España sin ningún tipo de documentación, porque a ninguna se les exigió visado (en 1996, año del estudio, llevaban en España entre siete y nueve años; Sara6, veintiuno, y Sara1, cuatro $)^{5}$. Así, parece que la falta de documentación no les supuso grandes problemas, sin embargo, sus complicaciones llegaron después, a la hora de hallar un empleo, de llegar a conocer la lengua. No obstante, algunas de ellas, por el hecho de proceder del norte de Marruecos, zona del ex-protectorado español, cercanas a Ceuta y a Melilla, tenían conocimientos básicos del castellano.

4. Actis, W.; Pereda, C.; DE PradA, M.R. (1994). Marroquins a Catalunya. Barcelona: ICEM.

5. Las mujeres entrevistadas pudieron haber regularizado su documentación durante la regularización excepcional de 1991, fecha clave, además, porque a partir de ella entra en vigor la exigencia del visado para los ciudadanos marroquíes. En cuanto a Sara1, contaba con un permiso de reagrupación familiar, ya que sus padres eran trabajadores agrícolas en Lérida. 
Las siete entrevistadas poseen ahora permiso de residencia, aunque sea mediante falsos contratos de trabajo, son los llamados «contratos encubiertos» en el servicio doméstico, pues legalmente constan como empleadas del servicio doméstico. Una de ellas ha conseguido además la nacionalidad española (Sara6). Algunas de las entrevistadas han sido llevadas a comisaría en diversas ocasiones, antes de haber obtenido los permisos de residencia. La dependencia de «los papeles» (especialmente del permiso de residencia), y por contrapartida el riesgo a exponerse a una situación de irregularidad en la calle, pone a la prostituta marroquí en peores condiciones de trabajo respecto a la prostituta española. Nuestras entrevistadas han pasado por períodos que no contaban con permisos de residencia, lo que les obligaba a ocultarse de la policía que patrulla el barrio, imposibilitando así que pudiesen denunciar los posibles problemas o agresiones de clientes o de otras personas de la calle.

Mientras realizaba este pequeño trabajo de campo, las entrevistadas se encontraban ya regularizadas, por lo cual pueden seguir esperando a sus clientes en la calle sin el peligro al que se exponen las recién llegadas.

\section{3. ¿Por qué emigran, en qué casos?}

La emigración marroquí está enmarcada dentro de las líneas migratorias de los países del Sur «subdesarrollado» hacia el Norte «desarrollado». Se trata, pues, de una migración básicamente conducida por motivos económicos, extraída de la asfixia que se produce en los países del Sur: la deuda externa en el Sur en conjunción con una determinada demanda de mano de obra en las economías más avanzadas del Norte.

Las mujeres marroquíes emigran hacia España. Unas lo hacen a través de la fórmula de la reunificación familiar; pero, otras, también solas (solteras, divorciadas, separadas o viudas con familia propia o sin familia). Todas con similares objetivos que el varón, desean alcanzar una mejora económica y desean alcanzar una mejora en sus condiciones de vida: «subir un escalón».

Muchas mujeres marroquíes están desarrollando estrategias migratorias para mejorar la situación de sus familias (a la vez que están provocando un cambio en la estructura social y familiar de origen). Las mujeres inmigrantes están configurando un nuevo modelo migratorio, y podría parecer que las inmigrantes marroquíes que inician un proceso migratorio no ligado a la reagrupación familiar, buscan objetivos más concretos que los inmigrantes varones y, tras su obtención, se aprecia incluso una tendencia al retorno.

\section{La inmigrante marroquí como prostituta en el Raval}

Las conversaciones con la policía nacional ubicada en el barrio señalaban que las prostitutas extranjeras eran en su mayoría mujeres latinoamericanas y de la Europa del Este. Respecto al barrio del Raval, decían que no había muchas mujeres extranjeras, puesto que el fenómeno de estos dos colectivos se centraba en la prostitución de carretera, dentro de los bares de alterne. 
Respecto a la figura del proxeneta ${ }^{6}$ marroquí, igualmente, nos confirma la policía que no se da el caso. No obstante, hemos oído rumores de que algunas mujeres prostitutas marroquíes están dirigidas por algún proxeneta marroquí, sobre todo con respecto a la recién llegada, que anda algo desorientada. Nosotros, en la observación del barrio, no hemos visto tampoco a los proxenetas, ni las prostitutas entrevistadas nos han hablado de ellos.

Alguna asistente social y una representante de una asociación de inmigrantes nos comentaban sorprendidas: «Prostitutas marroquíes prostitutas!». Señalaban que no parecía demasiado explicable o creíble que una marroquí se prostituyese, precisamente por su cultura religiosa. Si eso ocurre «deben ser tremendas las dificultades económicas que las empujan a ello».

En la asociación «Bayt al Thaqafa» (Casa de la Cultura) nos ponen al corriente sobre el hecho de la prostitución en Marruecos y nos comentan que «en ese país hay mucha prostitución, incluso de menores». Lo cual no quita que desde el punto de vista ético-religioso, la prostitución esté mal vista para un marroquí. No obstante, y según la entrevistada, cuando una persona necesita comer o tiene propuesto el objetivo de comer va a alcanzar su meta, aunque tenga para ello que saltarse según qué mandamientos divinos; a pesar de que se mantengan fieles a otros preceptos religiosos. Expresan también que la policía marroquí es tolerante incluso al hecho de que las madres se prostituyan, pues se cree que lo prioritario es que una madre pueda ofrecer de comer a sus hijos, por penalizado que sea el acto.

La prostitución existe también en Marruecos, nos dicen las mujeres de la asociación de mujeres marroquíes de Ca la Dona: «allí prostituyen a muchas mujeres, incluso a menores. Estas chicas son acostumbradas a un tipo de vida. Se permite que el hombre busque satisfacerse, y la belleza física de la mujer es cotizada y buscada para el placer sexual». Así, continúan: «aunque nosotras (las no prostitutas) no nos relacionemos con las mujeres prostitutas porque pensamos en otras salidas y valores para la mujer, sí sabemos que es y puede significar la prostitución en Marruecos o en España. Unas se prostituyen por dinero, otras, por papeles, aunque sea con un «amigo» 7 .

Varias vías conducen a la prostitución. Nadie, de nuestros entrevistados y entrevistadas, conoce la existencia de redes entre Marruecos y España que obliguen a mujeres a prostituirse. En contraposición con la organización de redes y proxenetismo, la prostitución de inmigrantes marroquíes en Barcelona parece ser de tipo voluntarista. Y según las fuentes oficiales, presentadas por la poli-

6. El proxenetismo se define como la actividad de inducir a la prostitución; es un acto considerado delito y así queda especificado en el artículo 452bis del Código Penal Español, sin que la prostitución esté condenada legalmente; en Tolivar, L. (1989). "Notas sobre la reglamentación, prohibición y tolerancia administrativa de la prostitución». Madrid: Revista española de derecho administrativo. CIVITAS, núm. 63.

7. En el argot de la prostitución, «amigo» se denomina al cliente fijo. Aunque, en este caso, nos referimos al amante, novio con el que se intercambia sexualidad y/o cariño por dinero o matrimonio por conveniencia legal (permisos de residencia). 
cía nacional del distrito: «las prostitutas marroquíes no se caracterizan por ser un grupo agredido. Se conocen, solamente, casos particulares (personales/individuales) de situaciones de denuncia».

Nosotros estaríamos de acuerdo quizás en que no es un colectivo propenso a sufrir agresiones, coacción de libertad. Pero sí que es un colectivo caracterizado por un número de problemas: principalmente su dependencia de la renovación de un permiso de residencia condicionado al trabajo (cuando la prostitución de calle no ofrece contrato) y su sometimiento al racismo, que en estos casos parece estar muy entrelazado con el ejercicio de la prostitución.

\section{Inducción a la prostitución}

¿Cómo entraron? Cansadas de aguantar en sus anteriores trabajos, limpiando más de ocho horas y sin conseguir ganar cantidades de dinero que les permitiesen enviar a sus familias o llevar otro tipo de vida, menos dependiente de un trabajo esclavo, en el que muchísimas veces son tratadas como inferiores («moras ladronas»).

La forma de reclutamiento se guía por una introducción en el trabajo a partir de otras compatriotas. Entre ellas, las amigas se tientan "por qué no probar suerte como putas, pues parece que se gana mucho dinero». Y así prueban, en España, lejos de sus familias y vecinos y vecinas, lo cual les cuesta superar una vergüenza inicial. Buscaban dinero: "poder ganar bastante más para ahorrar y enviar a la familia». La prostitución representa una forma de ganarse la vida, de la forma que más o menos necesitan. La mayoría de nuestras entrevistadas se dedican, ahora, exclusivamente a la prostitución. Sin embargo, Sara2 trabaja cuatro horas en la limpieza y cuatro en la prostitución (y como ella otras chicas, entre éstas sus compañeras de piso). También están las que "trapichean» (venden entre sus compañeras desde chicles a ropa hasta hachís), a la vez que se prostituyen.

Trabajan toda la semana, con tener un día o medio para ir a comprar y lavar, les es suficiente. Solamente dejan de trabajar cuando menstrúan. Unas piensan en retirarse con una edad tope; otras, cuando reúnan una cantidad fijada de ahorro; otras dicen que pronto, porque sus hijos están creciendo y pueden averiguarlo.

Para más de la mitad parece incierto su retiro (o su cambio de trabajo). Para ellas, no es tiempo de planteárselo y para una que se lo plantea, se siente muy incapaz de determinar su objetivo y el día límite. Dice Sara3: «Me iría mañana», no hoy, si tuviera dinero. Para ir a Marruecos necesito dinero. Allí todo es barato (eso sí pagando y se suman gastos), pero no hay dinero y se necesita dinero».

Las dificultades que encuentran en este trabajo, no son exclusivas de su tipo de ocupación. Si, ciertamente, a veces, aparece algún problema con algún cliente que no acepta el precio o el preservativo; o las españolas que se quejan de que ellas trabajan más barato. 
Nos apuntaba el ginecólogo de la calle Sant Ramon, la traición que se apreciaba entre las compañeras, en la rivalidad por obtener los mejores clientes. «Todo debido al entorno decadente que las rodea, y no solo a las prostitutas marroquíes, sino a todas las callejeras de la zona. Con falta de buenas condiciones laborales: empezando por la inexistencia de hoteles adecuados».

Sus problemas, nos dice alguna, son muchos, sin detallar. Apreciamos soledad y malestares indefinidos por la situación.

En el barrio ya son conocidas y no parece que se les diga nada, aunque alguna marroquí (no prostituta) no se comunique con éstas. Existen otras mujeres de la comunidad que sí, incluso viven con ellas. Les pesa más el estigma de mora (prejuicio racista) que el de puta. Se sienten rechazadas en general: «somos moras, ladronas» (Sara2). Entre las prostitutas del Raval, las prostitutas marroquíes son las «moras», y respecto al resto de la sociedad en general continúan siendo las «moras». Solo en el seno del colectivo inmigrante marroquí no son las «moras», en ese grupo a veces son «las putas», si es que alguien lo ha descubierto (alguien que no sea un confidente, que no será el que malhable normalmente), porque habitualmente esconden su actividad.

La prostitución es aceptada para estas mujeres. La razón es que se adaptan a una situación determinada; así no se piensa que se trate de una "cosa mala», a pesar de sus prejuicios iniciales y que les costase vergüenza empezar en el trabajo. En contraste con su aceptación individual, saben que por otra parte a otras personas de la comunidad les costará asumirlo, sobre todo si no se sienten demasiado cerca del fenómeno.

\section{Respecto a la regulación de la prostitución ejercida}

Todas las entrevistadas trabajan entre la calle y los bares, sin tener nada pactado con éstos últimos; la entrada al establecimiento es libre. Normalmente, están todas trabajando en los mismos puntos callejeros, aunque la mayoría ha probado las otras calles. Alguna de ellas ha estado alguna temporada, por conocer otras realidades, en clubes ${ }^{8}$ de otras zonas. Pero consideran que ya se han familiarizado con un lugar, han hecho «amigos» (clientes fijos) y siguen allí.

Una de las entrevistadas nos comenta que es posible que se «vaya a hacer plaza» a Ibiza (Sara4 o Sara5). Parece que entre las españolas jóvenes es una costumbre ir allí o a la costa (sobre todo en verano), y logran trabajar y ganar

8. En un club las mujeres están en el interior de un establecimiento, el cual es regido por un amo que las tiene contratadas (el contrato puede ser sólo verbal), y les ofrece una cantidad normalmente fija por relación. En los clubes, la mujer está protegida por la organización y orden puestos por la regencia del local, así como también se ofrece la posibilidad de revisiones médicas por un profesional que ofrece el club y que va periódicamente.

En la calle, las mujeres deben mostrarse, buscar los clientes, negociar precios, buscar cama... Se trata de una prostitución barata, mal pagada, en la que se encuentran algunas mujeres que no tienen muchas otras opciones. Por su cuenta deben buscarse ginecólogos, cosa que a veces, por falta de información y pereza, no se hace. 
bastante durante la estancia. Pero las otras parece que no tienen intenciones de moverse, excepto Sara3, que piensa en irse a un club, donde cree encontrará más seguridad.

Todas trabajan como independientes/autónomas, sin ningún «chulo» o patrón (proxeneta) ${ }^{9}$. Se quedan el dinero que ganan para ellas; dependiendo de la calle, todas cobran igual, para evitar rivalidades y peleas.

El precio mínimo en la calle Sant Ramon es de 2.000 pesetas (aunque se puede negociar menos, 1.000 pesetas, y se rumorea entre las españolas y las de las otras calles que se hace por 500 pesetas). En la calle D'en Robador, entre 3.000 y 4.000 , y en la Ronda, entre 4.000 y 5.000, y la cama es aparte, que la paga el cliente en todas las ocasiones (lo cual son entre 1.000 y 2.000, en la zona). Aunque hay clientes generosos que pagan más, si ellas aprecian a un tipo con posibilidades de pagar más, más piden. Así dicen, las que hacen negocio, que algunos días pueden ganar 20.000/25.000 pesetas, al igual que otros días nada (pues no siempre hay cliente).

De ese dinero, todas, excepto Sara4 (sus padres están en Lérida) y Sara6 (que lleva aquí 21 años, y tiene los hijos con ella), envían dinero para sus hijos en Marruecos. Sara1 y Sara3 envían imperdonablemente cada mes, y las demás dicen que cuando pueden y lo que pueden, pues en España hay más gastos, pero que intentan llevar al banco los ahorros. El enviar dinero a Marruecos significa que existe un tipo de relación estrecha entre ellas y sus orígenes (familia/país).

La salud es un tema importante, puesto que la mujer puede ser contagiada por algún cliente en todo lo que concierne a enfermedades de transmisión sexual. Parece tratarse de una población que no es portadora del virus del sida, que utiliza preservativo, que es consciente de la necesidad de su uso, aunque con un margen de tolerancia ante ciertos clientes. Ahora bien, no tienen el hábito de acudir a controles/revisiones sanitarios con regularidad, se dirigen a los servicios médicos cuando tienen algún problema, y en ocasiones, ni eso.

De siete entrevistadas, tres no hacen que se les practique ningún tipo de revisión ginecológica, aunque piensen que deben usar preservativo, por el miedo que tienen al sida. A pesar de no ser muy conscientes del hecho porque son de las que nos han afirmado que pueden llegar a no usarlo si el cliente así se lo pide (aunque se trate de muy pocas ocasiones). Pensamos que es considerable el número de tres mujeres, en proporción a las entrevistas realizadas. Existe necesidad de dotar de una mayor información respecto a la prostitución y sus riesgos sanitarios a la prostituta marroquí, teniendo en cuenta que la educación y práctica sexual en sus países de origen son distintas (y que pueden además, por el modus vivendi diferente, no estar inmunizadas, o mayor inmunizadas, que las prostitutas autóctonas ante ciertas enfermedades o malestares).

9. Así como el chulo (o rufián) sólo vive de la prostituta, el proxeneta facilita, coopera y protege la prostitución a cambio de un porcentaje monetario. No obstante, ambos personajes son considerados actores de delito para la legislación española. 
Las cuatro restantes acuden a distintos ginecólogos o ginecólogas privados para someterse a revisiones (y nos comentan que fuera del barrio; solamente Sara3 va al ginecólogo de la calle Sant Ramon) con una periodicidad mensual. Utilizan los servicios privados por la confianza que éstos les ofrecen.

Comentan que se sienten mucho mejor desde que se practican revisiones; están más tranquilas y, aunque reconozcan no tener mucha consciencia de las enfermedades de transmisión sexual, confían en su médico y piensan que con el preservativo no tiene que pasar nada.

\section{Respecto a la clientela}

La mayoría nos dice que acepta a todo el que quiera pagar la tarifa acordada. Algunas, primero valoran si les conviene el cliente y aceptan según les parece. Éstas que se fijan más en el tipo de cliente, evitan a los marroquíes; los definen como gente con poco dinero que se hallan en mala situación y que les causan un cierto respeto porque les recuerdan a su comunidad de origen: la familia, Marruecos, el control social.

El hombre marroquí, a su vez, tras una conversación tenida con algún cliente, prefiere a la prostituta española, con el fin de probar algo nuevo. No obstante, también es cierto que algunos chicos buscan a las marroquíes, con las que pueden hablar en marroquí; depende un poco de lo que se busque en la prostituta.

\section{La inaceptación moral de la prostitución}

La prostitución de calle es un trabajo para el que no hay contrato, por tanto no se necesitaría papeles, es una profesión a la que se dedican algunas mujeres que viven situaciones de marginalidad, como algunas inmigrantes. Es un medio que asegura unos recursos y no pide excesivos conocimientos, sólo algo de valor, que la persona toma según su personalidad y según su situación.

No obstante, la prostitución es una actividad tabú, y la mujer que la ejerce, la prostituta, queda marcada con el estigma de la que realiza una actividad socialmente ilegal (moralmente incorrecta para las culturas cristiana y musulmana). Consecuentemente, se considera a la prostituta una mujer fuera de la ley y una desviada social.

La inmigrante marroquí que se prostituye en el Raval, a pesar de haber optado por esta vía para realizar sus objetivos emigratorios (la mejora económica), y de llevarlos a cabo, es la cabeza de turco entre las demás prostitutas españolas que trabajan en un medio tan degradado como es la calle (donde es necesaria la aceptación de las prostitutas antiguas o con liderazgo para poder trabajar y la competencia desleal en búsqueda del cliente).

Esa misma mujer inmigrante va a tener que ocultar su trabajo en el seno de su familia o grupo de amistades, a los ojos de la comunidad marroquí, por- 
que sabe que la actividad realizada es considerada un pecado en el islam (zina $)^{10}$, representa la pérdida del honor ${ }^{11}$, es inaceptable socialmente, y bastante difícil es para ella tratar de interpretar y justificar su actitud, frente a esa necesidad personal de sentirse dentro de la corrección social.

\section{Bibliografía}

BOUSQUeT, G.H. (1953). La morale de lislam et son ethique sexuelle. París: Maisonneuve. Colectivo IOÉ (Actis, W.; Pereda, C.; De Prada, M.R.) (1994). Marroquins a Catalunya. Barcelona: ICEM.

CorTÉs, J. (trad.) (1992). El Corán. Nueva York: Tahrike Tarsile Qur’an.

Juliano, D. (1998). Las que saben. Subculturas de mujeres. Madrid: Horas y horas. RIBAS, N. (1996). La heterogeneidad de la integración social. Una aplicación a la inmigración extracomunitaria (filipina, gambiana y marroqui) en Cataluña (1985-1996). Tesis doctoral. Universitat Autònoma de Barcelona. Departament de Sociologia.

TOLIVAR, L. (1989). «Notas sobre la reglamentación, prohibición y tolerancia administrativa de la prostitución». Revista española de derecho administrativo. CIVITAS, núm. 63. Madrid.

10. Zina: relación sexual ilícita, es decir, toda relación sexual entre dos personas que no están ni legalmente casadas ni en régimen de concubinaje. Definición en BOUSQUET, G.H. (1953). La morale de l'islam et son ethique sexuelle. París: Maisonneuve.

11. CorTÉs, J. (trad.) (1992). El Corán (XVII, 32). Nueva York: Tahrike Tarsile Qur'an. 